\title{
Ionic liquids for the passive sampling of sulfonamides from water-applicability and selectivity study
}

\author{
Hanna Męczykowska ${ }^{1} \cdot$ Paulina Kobylis $^{1} \cdot$ Piotr Stepnowski $^{1} \cdot$ Magda Caban $^{1}$
}

Received: 2 August 2016/Revised: 17 March 2017 / Accepted: 27 March 2017 /Published online: 11 April 2017

(C) The Author(s) 2017. This article is published with open access at Springerlink.com

\begin{abstract}
Ionic liquids (ILs) are new-generation, non-volatile solvents which are designable, and their structure may be specifically adjusted to the current application needs. Therefore, it is possible to create and apply ILs which efficiently and selectively extract various analytes from different matrices. It has already been examined that ILs may be applied as receiving phases in passive sampling for the long-term water monitoring of PAHs and pharmaceuticals in water. In this paper, the concept of passive sampling with ILs (PASSIL applied as receiving phases) was continued and developed using phosphonium-, imidazolium-, and morpholinium-cation-based ILs. The target group of analytes was pharmaceuticals which represent one of the most common categories of water contaminants. Fourteen-day-long extractions using various ILs were performed in stirred conditions at a constant temperature $\left(20^{\circ} \mathrm{C}\right)$. The best extraction efficiency was achieved for trihexyl(tetradecyl)phosphonium dicyanamide ([P666$\left.14]\left[\mathrm{N}(\mathrm{CN})_{2}\right]\right)$. For this preliminary calibration, the sampling rates were calculated for each sulfonamide. Once again, selectivity was observed in passive sampling using [P666$14]\left[\mathrm{N}(\mathrm{CN})_{2}\right]$. Therefore, PASSIL is seen as a very promising method for pharmaceutical monitoring in water.
\end{abstract}

Electronic supplementary material The online version of this article (doi:10.1007/s00216-017-0342-6) contains supplementary material, which is available to authorized users.

Hanna Męczykowska

hanna.meczykowska@phdstud.ug.edu.pl

1 Institute for Environmental and Human Health Protection, Faculty of Chemistry, University of Gdansk, ul. Wita Stwosza 63, 80-308 Gdańsk, Poland
Keywords Ionic liquid · Passive sampling · PASSIL . Pharmaceuticals $\cdot$ Sulfonamides $\cdot$ Water monitoring

\section{Introduction}

The monitoring of pharmaceuticals is one of the fastest developing issues in current analytical chemistry in the field of environmental research. Pharmaceuticals are considered to be emerging pollutants due to their increasing consumption (considering expenditure and the volume or quantity of medicines consumed) [1], low removal efficiency in wastewater treatment plants [2], and negative impact on the life of water organisms [3]. For these reasons, data among various water contaminants should also be gathered for the monitoring of pharmaceuticals, according to the EU [4].

Sulfonamides (SAs) are one of the most widely used antibiotics [5, 6]. They are the second most commonly applied veterinary medicines in the European Union. These compounds are not completely metabolized; therefore, unmetabolized SAs and their metabolites are released into the environment [7]. Several studies confirmed that sulfonamides enter the environment by wastewater effluents [8] and can stream along with the surface or groundwater or remain in the soil [9]. Sulfonamides, like other pharmaceuticals, are monitored in water environments using various methods, like grab sampling [10-13], solid-phase extraction [14], the radioimmunoassay technique [15], micro-solid-phase extraction [16], or passive sampling (e.g., the polar organic chemical integrative sampler-POCIS technique) [17-19].

Passive sampling allows time-weighted average concentrations (TWACs) to be received, which are independent from random changes of environmental conditions [20-24]. 
Fig. 1 Ionic liquids applied during this study

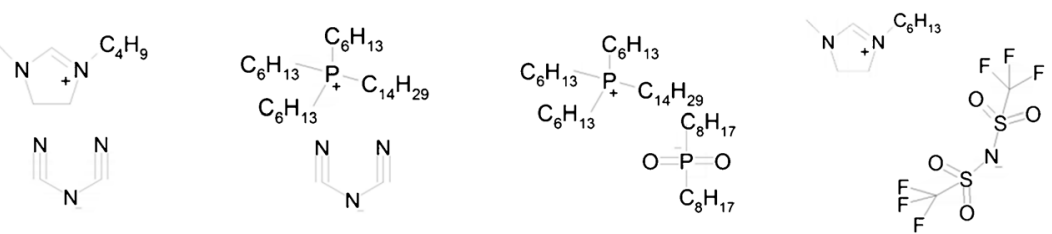

$$
\begin{aligned}
& \operatorname{BMIM~N}(\mathrm{CN})_{2}
\end{aligned}
$$

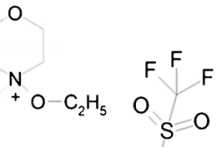

$$
\begin{aligned}
& \text { P666-14 N(CN })_{2} \\
& { }_{+\mathrm{C}_{3} \mathrm{H}_{6} \mathrm{OH}}^{\mathrm{O}} \mathrm{O}_{\mathrm{S}=\mathrm{O}}^{\mathrm{F}} \mathrm{F} \\
& \text { P666-14 }\left(\mathrm{C}_{8} \mathrm{H}_{17}\right)_{2} \mathrm{PO}_{2} \\
& \mathrm{C}_{6} \mathrm{H}_{13} \quad \mathrm{C}_{6} \mathrm{H}_{13} \\
& \mathrm{C}_{6} \mathrm{H}_{13} \\
& \mathrm{C}_{6} \mathrm{H}_{13}+\mathrm{C}_{14} \mathrm{H}_{29} \stackrel{\mathrm{F}}{\mathrm{F}} \mathrm{F} \\
& \stackrel{\mathrm{F}}{\mathrm{F}} \mathrm{S}_{\mathrm{S}}^{\mathrm{N}} \\
& \stackrel{\mathrm{F}}{\mathrm{F}} \mathrm{S}_{\mathrm{F}}^{\mathrm{N}} \\
& \begin{array}{l}
\mathrm{F} \\
\mathrm{F}
\end{array} \\
& \text { BMIM TFN } \\
& \mathrm{C}_{6} \mathrm{H}_{13} \\
& \underset{\mathrm{C}_{6} \mathrm{H}_{13}}{\mathrm{C}_{6} \mathrm{H}_{13}}+\underset{\mathrm{C}_{14} \mathrm{H}_{29}}{\mathrm{C}} \\
& \begin{array}{rlll}
\mathrm{C}_{2} \mathrm{~F}_{5} & \mathrm{~F} & \mathrm{C}_{2} \mathrm{~F}_{5} \\
\mathrm{~F} & \mathrm{P} & \mathrm{F} \\
& \mathrm{C}_{2} \mathrm{~F}_{5}
\end{array}
\end{aligned}
$$

Therefore, it is suitable for the long-term monitoring of contamination levels. Passive sampling techniques differ according to the receiving phase type. The most popular passive samplers contain divinylbenzene- $N$-vinylpyrrolidone copolymer (DVB-NVP) in pharmaceutical-POCIS, and modified silica (C18) in pesticide-POCIS and Chemcatcher [25-28].

Recently, we found that ionic liquids (ILs) may be applied as the liquid receiving phase in the passive sampling of PAHs [29] and selected pharmaceuticals [30]. ILs contain large, bulky, organic cations and significantly smaller organic or inorganic anions. Due to their unique structure, these salts are liquid in room temperature. Ionic liquids are also characterized by chemical and thermal stability and very good solvent properties, which are useful for passive sampling. The innovative technique of passive sampling was called passive sampling with ionic liquids (PASSIL). In the current study, passive sampling was performed for eight sulfonamides using phosphonium-, imidazolium-, and morpholinium-cation-based ionic liquids. The aim of this study was to find the proper ionic liquid which may be applied as the receiving phase for the passive sampling of these common water pollutants. It is expected that the PASSIL technique will allow for the dynamic and efficient extraction of pharmaceuticals from an aqueous medium.

\section{Materials and methods}

\section{Chemicals}

ILs were obtained from the University of Bremen (Germany) and Sigma-Aldrich (Germany) at a purity of $\geq 95 \%$. The ionic liquids applied were (Fig. 1) trihexyl (tetradecyl)phosphonium dicyanamide ([P666-14][N(CN) ]), trihexyl(tetradecyl)phosphonium tri(pentafluoroethyl) trifluorophosphate ([P666-14][( $\left.\left.\left(\mathrm{C}_{2} \mathrm{~F}_{5}\right)_{3} \mathrm{PF}_{3}\right]\right)$, trihexyl (tetradecyl)phosphonium dioctylphosphate [P666-14] $\left[\left(\mathrm{C}_{8} \mathrm{H}_{17}\right)_{2} \mathrm{PO}_{2}\right]$, trihexyl(tetradecyl)phosphonium bis (trifluoromethylsulfonyl)imide [P666-14][TFN],
Fig. 2 Sulfonamides applied as target analytes during PASSIL
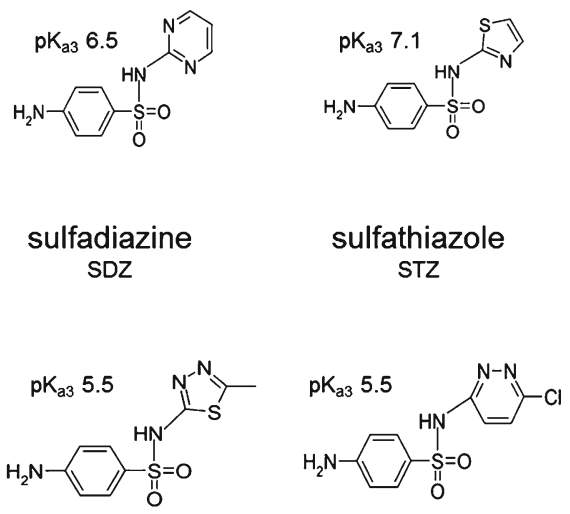

sulfamethizole SMT sulfachloropyridazine SCP

$$
\text { sulfathiazole }
$$

STZ
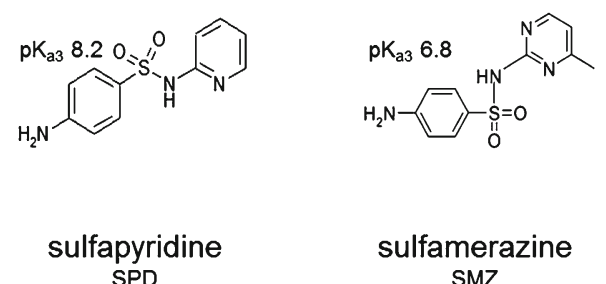

$\underset{\text { sulfamerazine }}{\text { SMZ }}$
the<smiles>Cc1cc(NS(=O)(=O)c2ccc(N)cc2)no1</smiles>

sulfamethoxazole SMX 
Fig. 3 Recovery (\%) of ionic liquids applied as receiving phases in PASSIL

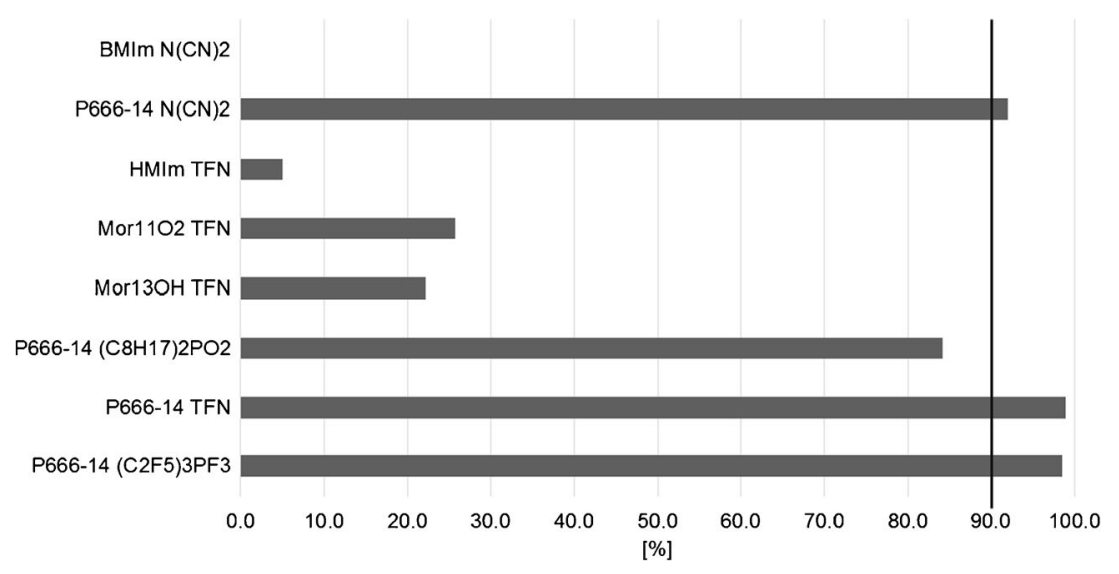

4-(etoxy)-4-methylmorpholinium bis(trifluoromethy 1 s u 1 fon 1 ) im ide ( [ M or $13 \mathrm{OH}][\mathrm{T} \mathrm{F} \mathrm{N} \mathrm{]),}$ 4-(hydroxypropyl)-4-methylmorpholinium bis(trifluoromethylsulfonyl)imide ([Mor1102][TFN]), and 1-butyl-3-methylimidazolium dicyanamide ([BMIm] $\left.\left[\mathrm{N}(\mathrm{CN})_{2}\right]\right)$.

Standards of SAs (Fig. 2), sulfathiazole (STZ), sulfamethiazole (SMT), sulfachloropyridazine (SCP), sulfamethoxazole (SMX), sulfadimethoxine (SDX), sulfadiazine (SDZ), sulfapyridine (SPD), and sulfamerazine (SMZ), were also purchased from Sigma-Aldrich (Germany). HPLC solvents, $n$-octanol, and ammonium acetate were obtained from POCH (Poland).

\section{Methods}

\section{Laboratory calibration using ultrapure water}

Passive sampling experiments were conducted analogously to previous studies [30]. The passive dosimeter was made of plexiglass and contained two polyethersulfone (PES) membranes with their inner sides covered with the receiving phase-ionic liquid (separately for each of the seven tested ILs) of a total mass equal to $200 \mathrm{mg}$. Nylon (Phenomenex) and Teflon (Merck) membranes were also tested. The donor phase was $100 \mathrm{~mL}$ of water solution with an initial sulfonamide concentration of $2 \mu \mathrm{g} \mathrm{mL}^{-1}$. The experimental setup was kept away from light radiation and at a constant temperature $\left(20^{\circ} \mathrm{C}\right)$. Each extraction lasted 14 days and the samples $(1 \mathrm{~mL})$ of the donor solution were collected every 2 days. The solution was stirred using a magnetic stirrer (1000 rpm), which was not renewed. After the experiment, the receiving phase was dissolved using $50 \mathrm{~mL}$ of acetonitrile. All the obtained samples (both from the donor and receiving phases) were analyzed by HPLC with a diode-array detector (DAD, Schimadzu, $272 \mathrm{~nm}$ ). The analysis was performed using a Gemini 5- $\mu \mathrm{m}$ C18 column (Phenomenex). The injection volume was $10 \mu \mathrm{L}$. The flow rate was $1.5 \mathrm{~mL} \mathrm{~min}^{-1}$. Acetonitrile (ACN) was used as the organic component of the mobile phase, and the aqueous component was an acetate buffer $\left(5 \mathrm{mmol} \mathrm{L}^{-1}\right.$ $\mathrm{CH}_{3} \mathrm{COONH}_{4}, \mathrm{pH}=4$ ) with $5 \%$ of $\mathrm{ACN}$. The mobile phase gradient was applied. The recovery of the receiving phase, the extraction efficiency, and the sampling rate (for [P666-14][N $\left.(\mathrm{CN})_{2}\right]$ ) were calculated for each analyte according to the equations presented in [30]. Moreover, micrographs using a HITACHI S-3400N scanning electron microscope (SEM) were taken to
Fig. 4 Relation between the efficiency of the passive sampling extraction of sulfonamides with $[\mathrm{P} 666-14]\left[\mathrm{N}(\mathrm{CN})_{2}\right]$ as the receiving phase, and the membrane types (PES, nylon, or PTFE)

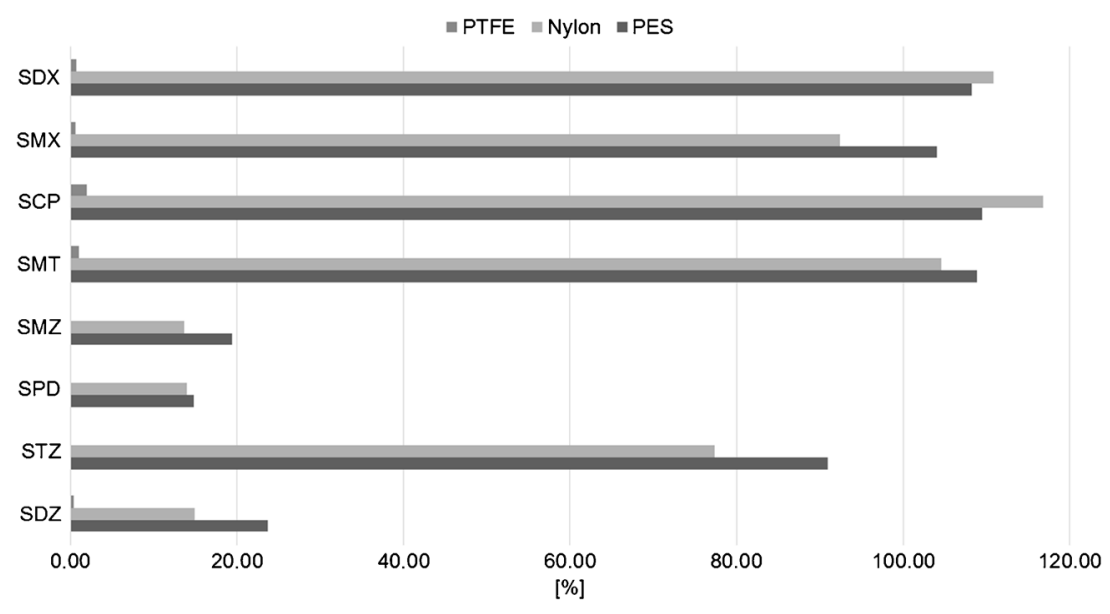




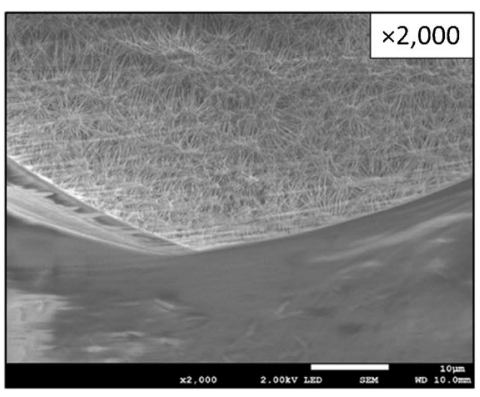

a

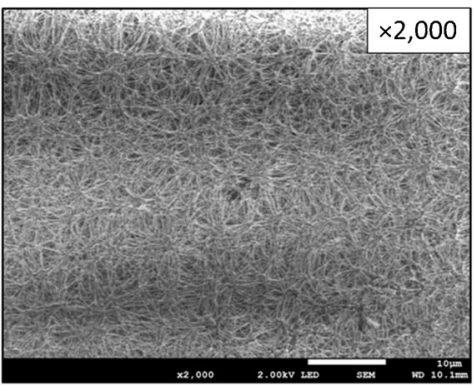

b

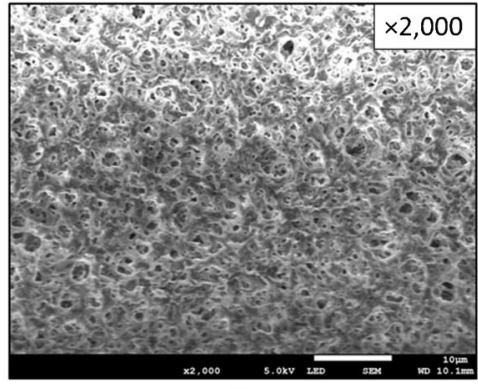

C

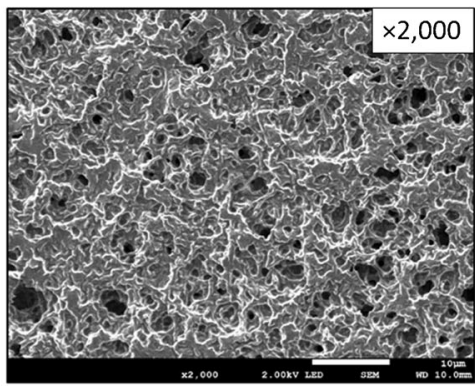

d

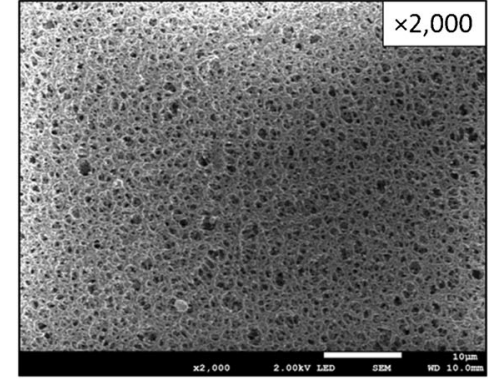

e

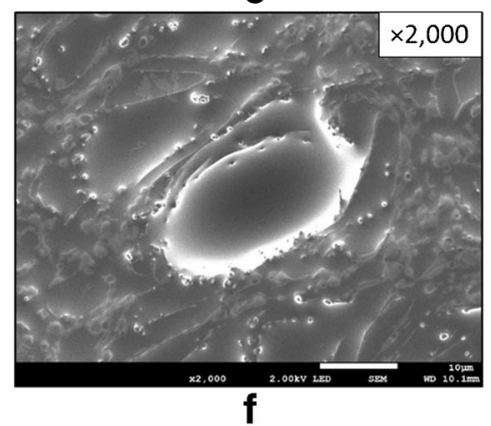

Fig. 5 SEM micrographs of PTFE membranes uncovered (a) and covered (b) with an ionic liquid, nylon membranes uncovered (c) and covered (d) with an ionic liquid, and PES membranes uncovered (e) and covered (f) with an ionic liquid [P666-14][N(CN) $)_{2}$

study the morphological appearance of the membranes covered with an ionic liquid [P666-14][N(CN) 2 .

\section{Laboratory calibration using environmental water samples}

Two types of environmental water samples were collected: surface water and secondary effluent. The first one was collected from the Oliwski Stream, and the second one was obtained from a wastewater treatment plant "Wschód" in Gdańsk. All collected samples were stored at $4{ }^{\circ} \mathrm{C}$ and kept out of light radiation. Before the extraction, water and effluent samples were filtrated using a glass filtration set (Sartorius, Germany) with glass fiber filters.

Four extractions of pharmaceuticals from the surface water were conducted, two in $1 \mathrm{~L}$ of raw water and another two in $1 \mathrm{~L}$ of water spiked with eight SAs to obtain an initial concentration of $2 \mu \mathrm{g} \mathrm{L}{ }^{-1}$. Simultaneously, another four extractions of sulfonamides from sewage water were performed, likewise in raw and spiked $(2 \mu \mathrm{g}$ per $100 \mathrm{~mL}$ ) water of total volume $100 \mathrm{~mL}$ each. Passive dosimeters were prepared just like during the calibration in ultrapure water. Each experiment lasted 7 days and samples $(0.5 \mathrm{~mL})$ were collected every $24 \mathrm{~h}$. HPLC analysis was conducted analogously to previous PASSIL experiments.

\section{Determining $\log K_{O W}$ and $\log D_{O W}$ values}

The octanol-water coefficient $\left(K_{\mathrm{OW}}\right)$ can be defined as the ratio of the compound concentration between an organic solvent (usually $n$-octanol) saturated with water and an aqueous phase (e.g., water saturated with $n$-octanol) [31]. The coefficient is usually used in a $\operatorname{logarithmic}$ form $\left(\log K_{\mathrm{OW}}\right)$. However, this value does not vary in
Fig. 6 The concentration of sulfonamides in a water solution during passive sampling with PES membranes and [P666-14][N $(\mathrm{CN})_{2}$ ] applied as a receiving phase (experiment conducted in triplicate)

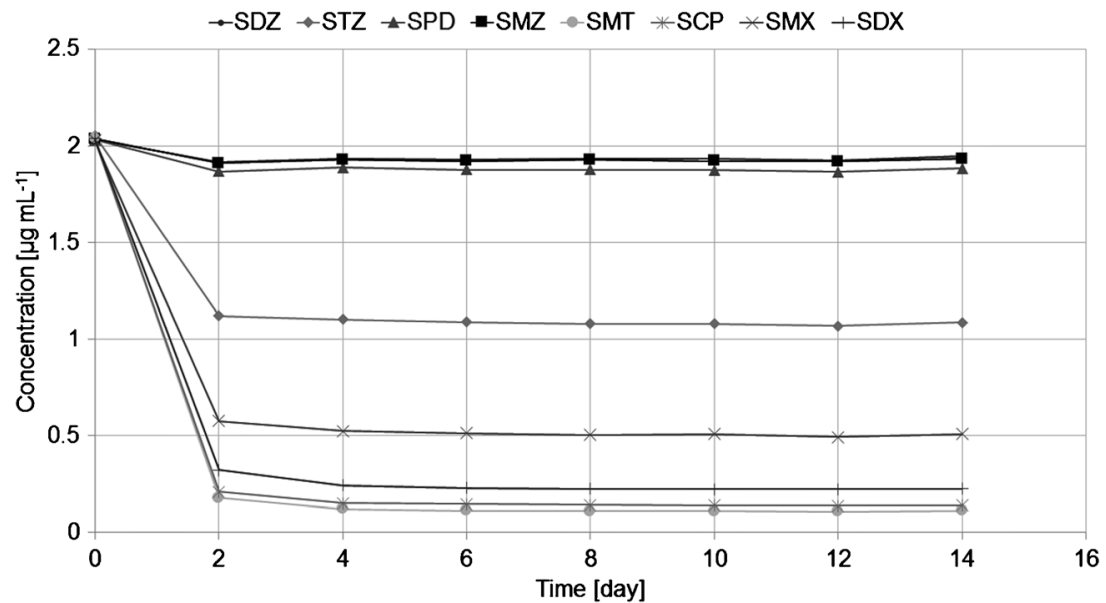




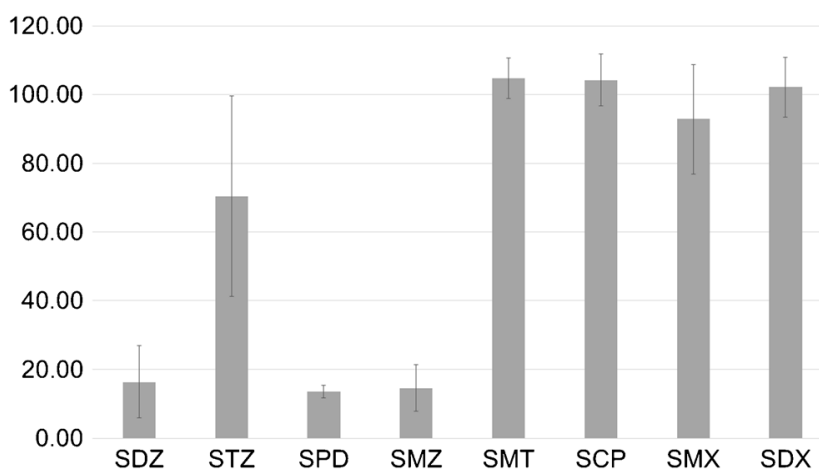

Fig. 7 Sulfonamide extraction efficiencies obtained from PASSIL experiments carried out using ultrapure water

the context of various forms of ionization of the analyte. Therefore, to solve this issue, the $K_{\mathrm{OW}}$ may be additionally multiplied by the $f_{\mathrm{n}}$ factor (fraction of neutral molecule). The received value is $D_{\mathrm{OW}}$ ( $\mathrm{pH}$-adjusted octanol-water distribution coefficient), also applied in the logarithmic form $\left(\log D_{\mathrm{OW}}\right)$. $D_{\mathrm{OW}}$ may be defined as the ratio of the concentrations of both the ionized and unionized species of the compound in the organic and aqueous phases at a specific $\mathrm{pH}$ value. During this study, the $\log D_{\text {Ow }}$ values were determined experimentally for all tested antibiotics. Solutions of each sulfonamide were prepared separately at a concentration of $100 \mu \mathrm{g} \mathrm{mL}^{-1}$ in methanol. The obtained solutions were diluted with ultrapure water ( $\mathrm{pH}$ 5.6) previously saturated with octanol to obtain a concentration of $5 \mu \mathrm{g} \mathrm{mL}^{-1}$. Equal volumes of the prepared solutions and octanol saturated with water were shaken and allowed to settle at room temperature in order to separate two clear layers. Then, $0.5 \mathrm{~mL}$ of the water layer of each sample was taken and analyzed by HPLC/DAD (272 nm). On the basis of this experiment, the $\log K_{\text {OW }}$ and $\log D_{\text {OW }}$ values were calculated [32].

\section{Results and discussion}

\section{Stability of ILs inside the PASSIL dosimeter}

The basic parameter of an applied ionic liquid is its physical stability inside the homemade dosimeter expressed by the IL recovery $(\%)$ calculated from the difference between ionic liquid masses before and after the passive sampling. The highest recovery (more than 90\%) of ionic liquids was achieved by phosphonium-cation-based ILs and PES membranes (Fig. 3). The recoveries were $98.9 \%$ for [P666-14][TFN], 98.5\% for [P666-14] $\left[\left(\mathrm{C}_{2} \mathrm{~F}_{5}\right)_{3} \mathrm{PF}_{3}\right]$, and $92.4 \%$ for $[\mathrm{P} 666-14]\left[\mathrm{N}(\mathrm{CN})_{2}\right]$. The type of cation seems to have a bigger impact on the stability of the tested ILs, which was found after a comparison of the results for bis(trifluoromethylsulfonyl)imide (TFN)-based ILs.

Among all the examined ionic liquids, trihexyl(tetradecyl)phosphonium dicyanamide [P666-14][N(CN) 2$]$ was characterized as having the third best recovery, although it allowed for the best efficiency of the extraction of sulfonamides. Also, [P666-14][N $(\mathrm{CN})_{2}$ ] contains no fluorine atoms; therefore, it is less toxic for living organisms than the other two ionic liquids, which contain fluorinated anions [33]. Thereby, during further experiments, $[\mathrm{P} 666-14]\left[\mathrm{N}(\mathrm{CN})_{2}\right]$ was applied.

\section{Nylon, PTFE, and PES membrane application}

The next step was to examine the influence of membrane types for the extraction of SAs using the previously selected ionic liquid. It was confirmed that the best membranes are nylon and PES (Fig. 4). The application of polytetrafluoroethylene (PTFE) membranes results in a very low concentration or lack of analytes in the receiving phase.

The applicability of nylon and PES membranes for PASSIL was confirmed also by the SEM micrographs (Fig. 5). However, the coating with an ionic liquid was the best for the polyethersulfone (PES) membrane - almost all of the pores were filled with the acceptor phase (Fig. 5). For nylon, the membrane coating was visibly smaller. For PTFE, almost no coating was observed. The hydrophobicity of PES membranes is relatively small compared to that of the other tested types, but the covering with hydrophobic ILs was satisfying.

Control experiments (membranes without a receiving phase) were performed. PES membranes do not significantly adsorb the analytes on their surface $(\leq 12 \%)$, while other membranes participate in the extraction of analytes. Finally, the membrane selected
Table 1 The ionization degrees, $\log K_{\mathrm{OW}}$, and $\log D_{\mathrm{OW}}$ of sulfonamides (initial $\mathrm{pH}$ 5.64)

\begin{tabular}{lllccll}
\hline Parameter & $\mathrm{pKa}_{2}$ & $\mathrm{pKa}_{3}$ & $\alpha 2[\%]$ & $\alpha 3[\%]$ & $\log K_{\text {OW }}(\exp )$ & $\log D_{\text {OW pH 5.6 }}(\exp )$ \\
\hline SDZ & 1.8 & 6.5 & 100.0 & 12.1 & -0.34 & -0.39 \\
STZ & 2.1 & 7.1 & 100.0 & 3.4 & -0.16 & -0.17 \\
SPD & 2.4 & 8.2 & 99.9 & 0.3 & 0.04 & 0.04 \\
SMZ & 1.8 & 6.8 & 100.0 & 6.5 & 0.19 & 0.16 \\
SMT & 1.8 & 5.5 & 100.0 & 58.0 & 0.01 & -0.34 \\
SCP & 2.2 & 5.5 & 100.0 & 58.0 & 0.36 & 0.00 \\
SMX & 1.8 & 5.7 & 100.0 & 46.6 & -0.19 & -0.44 \\
SDX & 2.5 & 5.9 & 99.9 & 35.5 & 0.59 & 0.42 \\
\hline
\end{tabular}


Fig. 8 Ionization states of sulfapyridine<smiles>[Y5]Nc1ccc(S(=O)(=O)Nc2ccccn2)cc1</smiles>

for PASSIL experiments was PES. The same membrane type is also used in the POCIS technique [34].

Figure 6 shows the change in the concentration of target SAs in a water phase in 14-day controlled experiments. The most significant analyte concentration drop takes place between the first and second sample collections, similarly to the results from previous investigations for different pharmaceutical types [30]. The drop in concentration (difference between the compound concentration in the donor solution before and after passive sampling) for SMZ and SPD was negligible, while for STZ it was close to $50 \%$. For the rest of the analytes, the drop was more significant (75 to $95 \%$ ).

\section{PASSIL calibration}

The sampling rates (see Electronic Supplementary Material (ESM) Table S1) $\left(R_{\mathrm{s}}\right.$ defined as the volume of water purified from the analyte per unit of time [ $\left.\mathrm{L} \mathrm{day}^{-1}\right]$ ) could be calculated only for analytes whose concentration decrease was greater than $50 \%$ (analogously to previous research [30]). The values of sampling rates varied between 0.61 and $0.92 \mathrm{~L}^{\text {day }}{ }^{-1}$. These numbers are minimum four times higher than analogous results obtained from POCIS experiments [35-37]. This means that the change of the receiving phase from solid to liquid can make passive sampling more efficient. It is very important that the membranes' pores and surface are covered by the IL, which can directly interact with the analytes. In the POCIS technique, the analytes need to firstly pass through the membrane pores. In the PASSIL technique, the role of the membrane is just to support the liquid receiving phase.

\section{PASSIL selectivity}

The selectivity of PASSIL performed using [P666-14][N $(\mathrm{CN})_{2}$ ] needs to be discussed. The factors which are responsible for the low extraction efficiency of SDZ, SPN, and SMZ (Fig. 7) are sure to come from the side of the analytes, and the $\mathrm{pKa}$ and $\log K_{\mathrm{OW}}$ are the most probable factors.

Sulfonamides have three $\mathrm{pKa}$ values [38], but only two and three are valid for this study. The lowest values of $\mathrm{pKa}$ of the analytes are in the range from 5.5 (for SMT and SCP) to 5.9 (for SDX) (Table 1). For these SAs, more than $35.5 \%$ of particles are charged negatively (calculated using equations in [39]), and the extraction efficiency is higher than 60\%. Also, for sulfathiazole ( $\mathrm{pKa}_{3} 7.1$ ), the efficiency is higher than $50 \%$, although its neutral form dominates in the donor solution.

For other analytes, whose $\mathrm{pKa}_{3}$ is higher than the $\mathrm{pH}$ value of the donor solution, the negatively charged form is present in less than $13 \%$ (for SPD, it is less than 1\%) (Fig. 8) and their passive sampling efficiencies are lower than $20 \%$. Thereby, it was assumed that the negative form of the analyte was favored during passive sampling.

In 2011, Li et al. [25] examined the influence of different $\mathrm{pH}$ values of the donor solution on the sampling rates for POCIS of estrogens, anti-depressants, $\beta$-blockers, and other pharmaceuticals. For acidic pharmaceuticals, the sampling rates decreased along with an increase in the donor solution $\mathrm{pH}$ from 3 to 9 . The opposite situation was observed for basic analytes. In both cases, the sampling rates were higher when the neutral form of the target compound prevailed. For naproxen, the highest $R_{\mathrm{s}}$ value ( $\mathrm{pKa} 4.20$ [40]) was calculated at $\mathrm{pH} 3$, while for nadolol ( $\mathrm{pKa} 9.69$ [41]), at pH 9. Therefore, it appears that the dependencies during POCIS and PASSIL passive sampling are different, which was assumed.

The sampling rate values are also influenced by the hydrophobicity of the analytes. Lipophilicity is usually measured by the octanol-water (partition) coefficient $\left(K_{\mathrm{OW}}\right)$ ("Methods" section). However, how it was already mentioned, for ionizable compounds at a $\mathrm{pH}$ at which they are partially ionized,
Fig. 9 Sulfonamide extraction efficiencies obtained from PASSIL experiments conducted using real environmental water samples

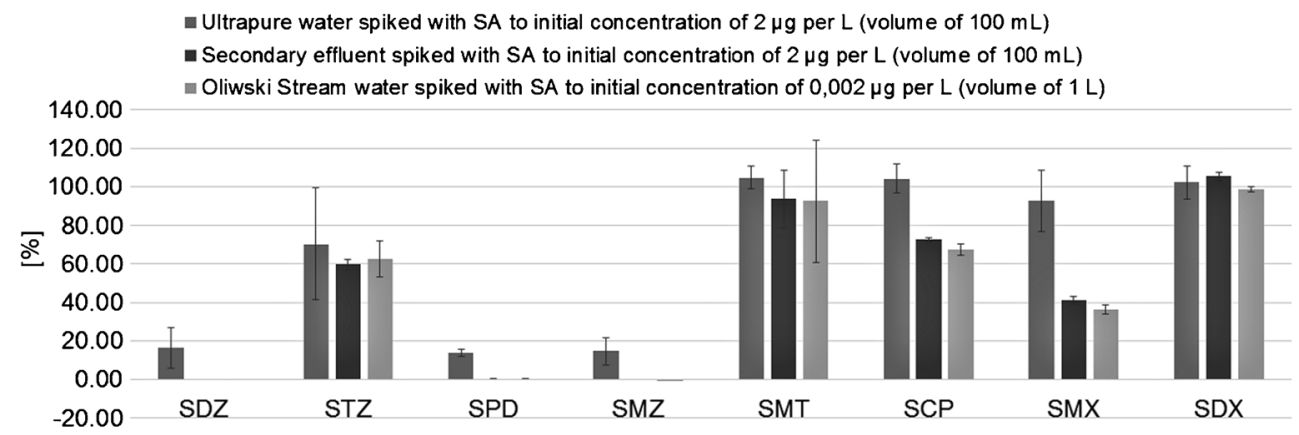


the concentration in both phases is related to the distribution coefficient $(D)$. Therefore, for sulfonamides, both coefficients (presented as $\log K_{\mathrm{OW}}$ and $\log D_{\mathrm{OW}}$ ) were determined experimentally and calculated according to [32]. Generally, the more hydrophobic SAs are extracted more efficiently; however, no direct proportional dependencies between PASSIL efficiency and $\log K_{\mathrm{OW}}$ or $\log D_{\mathrm{OW}}$ values of SAs were noticed.

\section{PASSIL from environmental matrices}

The PASSIL technique has been also used for extraction of sulfonamides from environmental matrices ("Methods" section). The recovery (\%) of SAs from water samples collected from Oliwski Stream (Gdansk, Poland) and secondary effluent (Gdansk, Poland) is presented in Fig. 9.

First of all, the change of donor solution from ultrapure water to environmental matrix did not affect the efficiency of PASSIL in the case of STZ, SMT, and SDX. For the rest of the analytes (SDZ, SPD, and SMZ), increased salinity (con-

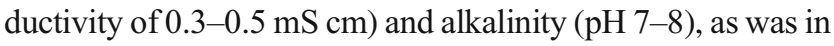
the case of the use of both environmental matrices, caused a significant decrease of extraction efficiency. The most saline donor solution (water from Oliwski Stream) caused the most decrease.

Moreover, applying different SA concentrations (2 and $0.002 \mu \mathrm{g} \mathrm{L}^{-1}$ ) also has not influenced the PASSIL efficiency (Fig. 9). Obtained results are compatible with those obtained from POCIS. Togola and Budzinski [42] and DiCarro [43] investigated the initial analyte concentration impact on the $R_{\mathrm{S}}$ of pharmaceuticals. Both teams have not observed any direct dependencies between the concentration of the compound and its extraction efficiency [44]. Therefore, it is stated that PASSIL passive sampler laboratory calibrations, likewise POCIS, may be performed at higher analyte concentrations $\left(\mu \mathrm{g} \mathrm{L}^{-1}\right)$ than are present in the water environment-pharmaceutical concentrations in river water are usually lower than $500 \mathrm{ng} \mathrm{L}^{-1}$.

Additionally, the sampling rates $\left(R_{\mathrm{S}}\right)$ for effluent samples were calculated, however only for sulfonamides characterized by a significant $(>50 \%)$ concentration drop of the donor solution: $0.8 \mathrm{~L}^{-1 a y}{ }^{-1}$ for STZ and SMT, $0.59 \mathrm{~L} \mathrm{day}^{-1}$ for SCP, and $0.45 \mathrm{~L} \mathrm{day}^{-1}$ for SDX. All presented values are higher than those obtained from POCIS calibration experiments held in different environmental conditions [44].

\section{Conclusions}

PASSIL is a novel technique which may be applied for the passive sampling of pharmaceuticals from water. Among the tested imidazolium-, morpholinium-, and phosphonium-cation-based ionic liquids, [P666-14][N(CN $\left.)_{2}\right]$ is characterized by the best acceptor properties. The extraction efficiencies of SAs obtained using PASSIL, both using ultrapure and environmental water, were higher than those received using POCIS (conducted with similar test conditions). As it was already suspected after previous experiments, PASSIL is a selective method of long-term water monitoring. The PASSIL selectivity is most probably based on the ionization degree of the analytes (in this case sulfonamides). The best efficiencies were obtained for more acidic SAs, whose negatively charged form prevails in the donor water solution $(\mathrm{pH} 5.5 \pm 0.1)$. The PASSIL applicability, mechanism, and variability will be the subject of further research.

Acknowledgements Financial support was provided by the National Science Center under grant UMO-2015/17/D/ST4/00774.

\section{Compliance with ethical standards}

Conflict of interest The authors declare that they have no conflict of interest.

Open Access This article is distributed under the terms of the Creative Commons Attribution 4.0 International License (http:// creativecommons.org/licenses/by/4.0/), which permits unrestricted use, distribution, and reproduction in any medium, provided you give appropriate credit to the original author(s) and the source, provide a link to the Creative Commons license, and indicate if changes were made.

\section{References}

1. OECD. Pharmaceutical consumption. Heal glanceEurope. 2012;2012:88-9.

2. Santos LHMLM, Gros M, Rodriguez-Mozaz S, Delerue-Matos C, Pena A, Barceló D, et al. Contribution of hospital effluents to the load of pharmaceuticals in urban wastewaters: identification of ecologically relevant pharmaceuticals. Sci Total Environ. 2013;461462C:302-16.

3. Schmidt W, O'Rourke K, Hernan R, Quinn B. Effects of the pharmaceuticals gemfibrozil and diclofenac on the marine mussel (Mytilus spp.) and their comparison with standardized toxicity tests. Mar Pollut Bull. 2011;62(7):1389-95.

4. The European Parlament and the Council of the European Union. DIRECTIVE 2013/39/EU OF THE EUROPEAN PARLIAMENT AND OF THE COUNCIL of 12 August 2013 amending Directives 2000/60/EC and 2008/105/EC as regards priority substances in the field of water policy. Off J Eur Union. 2013;226(July):1-17.

5. Białk-Bielińska A, Stolte S, Arning J, Uebers U, Böschen A, Stepnowski P, et al. Ecotoxicity evaluation of selected sulfonamides. Chemosphere. 2011;85(6):928-33.

6. Hruska K, Frank M. Sulfonamides in the environment: a review and a case report. Vet Med (Praha). 2012;57(1):1-35.

7. Sukul P, Spiteller M. Sulfonamides in the environment as veterinary drugs. Rev Environ Contam Toxicol. 2006;187:67-101.

8. Díaz-Álvarez M, Barahona F, Turiel E, Martín-Esteban A. Supported liquid membrane-protected molecularly imprinted beads for micro-solid phase extraction of sulfonamides in environmental waters. J Chromatogr A. 2014;1357:158-64.

9. Kümmerer K. Antibiotics in the aquatic environment-a reviewpart I. Chemosphere. 2009;75(4):417-34. 
10. Leung $\mathrm{H}$, Jin L, Wei S, Tsui M. Pharmaceuticals in tap water: human health risk assessment and proposed monitoring framework in China. Environ Heal Perspec. 2013;121(7):839.

11. Zhu S, Chen H, Li J. Sources, distribution and potential risks of pharmaceuticals and personal care products in Qingshan Lake basin. Eastern China Ecotoxicol Environ Saf. 2013;96:154-9.

12. Holm JV, Rugge K, Bjerg PL, Christensen TH. Pharmaceutical organic compounds in the groundwater downgradient of a landtill. Environ Sci Technol. 1995;29(5):1415-20.

13. Lindberg RH, Wennberg P, Johansson MI, Tysklind M, Andersson BAV. Screening of human antibiotic substances and determination of weekly mass flows in five sewage treatment plants in Sweden. Environ Sci Technol. 2005;39(10):3421-9.

14. Agunbiade FO, Moodley B. Pharmaceuticals as emerging organic contaminants in Umgeni River water system, KwaZulu-Natal, South Africa. Environ Monit Assess. 2014;186(11):7273-91.

15. Yang S, Carlson K. Routine monitoring of antibiotics in water and wastewater with a radioimmunoassay technique. Water Res. 2004;38(14-15):3155-66.

16. Zhou Q, Fang Z. Highly sensitive determination of sulfonamides in environmental water samples by sodium dodecylbenzene sulfonate enhanced micro-solid phase extraction combined with high performance liquid chromatography. Talanta. 2015;141:170-4.

17. Jaimes-Correa JC, Snow DD, Bartelt-Hunt SL. Seasonal occurrence of antibiotics and a beta agonist in an agriculturallyintensive watershed. Environ Pollut. 2015;205:87-96. Available from: http://linkinghub.elsevier.com/retrieve/pii/ S0269749115002560

18. Li H, Helm PA, Metcalfe CD. Sampling in the great lakes for pharmaceuticals, personal care products, and endocrine-disrupting substances using the passive polar organic chemical integrative sampler. Environ Toxicol Chem. 2010;29(4):751-62.

19. Shi X, Zhou JL, Zhao H, Hou L, Yang Y. Application of passive sampling in assessing the occurrence and risk of antibiotics and endocrine disrupting chemicals in the Yangtze Estuary. China Chemosphere. 2014;111:344-51.

20. Rujiralai T, Bull ID, Llewellyn N, Evershed RP. In situ polar organic chemical integrative sampling (POCIS) of steroidal estrogens in sewage treatment works discharge and river water. J Environ Monit. 2011;13(5):1427-34.

21. Morin N, Camilleri J, Cren-Olivé C, Coquery M, Miège C. Determination of uptake kinetics and sampling rates for 56 organic micropollutants using "pharmaceutical" POCIS. Talanta. 2013;109:61-73.

22. Ibrahim I, Togola A, Gonzalez C. In-situ calibration of POCIS for the sampling of polar pesticides and metabolites in surface water. Talanta. 2013;116:495-500.

23. Namieśnik J, Zabiegała B, Kot-Wasik A, Partyka M, Wasik A. Passive sampling and/or extraction techniques in environmental analysis: a review. Anal Bioanal Chem. 2005;381(2):279-301.

24. Kot-Wasik A, Zabiegała B, Urbanowicz M, Dominiak E, Wasik A, Namieśnik J. Advances in passive sampling in environmental studies. Anal Chim Acta. 2007;602(2):141-63.

25. Li H, Helm PA, Paterson G, Metcalfe CD. The effects of dissolved organic matter and $\mathrm{pH}$ on sampling rates for polar organic chemical integrative samplers (POCIS). Chemosphere. 2011;83(3):271-80.

26. Arditsoglou A, Voutsa D. Passive sampling of selected endocrine disrupting compounds using polar organic chemical integrative samplers. Environ Pollut. 2008;156(2):316-24.
27. Ahrens L, Daneshvar A, Lau AE, Kreuger J. Characterization of five passive sampling devices for monitoring of pesticides in water. J Chromatogr A. 2015;1405:1-11.

28. Vrana B, Mills GA, Dominiak E, Greenwood R. Calibration of the Chemcatcher passive sampler for the monitoring of priority organic pollutants in water. Environ Pollut. 2006;142(2):333-43.

29. Maszkowska J, Synak E, Fabiańska A, Caban M, Stolte S, Husson $\mathrm{P}$, et al. Preliminary study on suitability of ionic liquids as potential passive-sampling media of polyaromatic-hydrocarbon (PAH) analyses in water. Anal Bioanal Chem. 2015;407(12):3531-6.

30. Caban M, Męczykowska H, Stepnowski P. Application of the PASSIL technique for the passive sampling of exemplary polar contaminants (pharmaceuticals and phenolic derivatives) from water. Talanta. 2016;155:185-92.

31. Andrés A, Rosés M, Ràfols C, Bosch E, Espinosa S, Segarra V, et al. Setup and validation of shake-flask procedures for the determination of partition coefficients ( $\log \mathrm{D})$ from low drug amounts. Eur J Pharm Sci. 2015;76:181-91.

32. Wu X, Ernst F, Conkle JL, Gan J. Comparative uptake and translocation of pharmaceutical and personal care products (PPCPs) by common vegetables. Environ Int. 2013;60:15-22.

33. Steudte $\mathrm{S}$. Investigations on the stability and ecotoxicity of selected ionic liquid cations and anions, $\mathrm{PhD}$ thesis. 2013;1-203-NaN-0.

34. Vermeirssen ELM, Dietschweiler C, Escher BI, van der Voet J, Hollender J. Transfer kinetics of polar organic compounds over polyethersulfone membranes in the passive samplers POCIS and Chemcatcher. Environ Sci Technol. 2012;46(12):6759-66.

35. MacLeod SL, McClure EL, Wong CS. Laboratory calibration and field deployment of the polar organic chemical integrative sampler for pharmaceuticals and personal care products in wastewater and surface water. Environ Toxicol Chem. 2007;26(12):2517-29.

36. Brown DL. Use of passive samplers to evaluate pharmaceutical fate in surface waters. 2010;91.

37. Bartelt-Hunt SL, Snow DD, Damon-Powell T, Brown DL, Prasai G, Schwarz M, et al. Quantitative evaluation of laboratory uptake rates for pesticides, pharmaceuticals, and steroid hormones using POCIS. Environ Toxicol Chem. 2011;30(6):1412-20.

38. Bialk-Bielińska A, Stolte S, Matzke M, Fabiańska A, Maszkowska $\mathrm{J}$, Kołodziejska M, et al. Hydrolysis of sulphonamides in aqueous solutions. J Hazard Mater. 2012;221-222:264-74.

39. Atkins PW. Physical chemistry. Oxford University Press; 2010.

40. Azzouz A, Ballesteros E. Combined microwave-assisted extraction and continuous solid-phase extraction prior to gas chromatographymass spectrometry determination of pharmaceuticals, personal care products and hormones in soils, sediments and sludge. Sci Total Environ. 2012;419:208-15.

41. Maszkowska J, Stolte S, Kumirska J, Łukaszewicz P, Mioduszewska K, Puckowski A, et al. Beta-blockers in the environment: part II. Ecotoxicity study. Sci Total Environ. 2014;493: $1122-6$.

42. Togola A, Budzinski H. Development of polar organic integrative samplers for analysis of pharmaceuticals in aquatic systems. Anal Chem. 2007;79(17):6734-41.

43. Di Carro M, Bono L, Magi E. A simple recirculating flow system for the calibration of polar organic chemical integrative samplers (POCIS): effect of flow rate on different water pollutants. Talanta. 2014;120:30-3.

44. Męczykowska H, Kobylis P, Stepnowski P, Caban M. Calibration of passive samplers for the monitoring of pharmaceuticals in water-sampling rate variation. Crit Rev Anal Chem. 2016;47:1-19. 